\title{
Estimating the Local Time of Emergence of Climatic Variables Using an Unbiased Mapping of GCMs: An Application in Semiarid and Mediterranean Chile
}

\author{
CRISTIÁN CHADWICK \\ Facultad de Ciencias Forestales y de la Conservación de la Naturaleza, Universidad de Chile, Santiago, Chile \\ JORGE GIRONÁS \\ Departamento de Ingeniería Hidráulica y Ambiental, and Centro Interdisciplinario de Cambio Global, Pontificia \\ Universidad Católica de Chile, and Centro Nacional de Investigación para la Gestión Integrada de Desastres \\ Naturales, CONICYT/FONDAP/15110017, and Centro de Desarrollo Urbano Sustentable, \\ CONICYT/FONDAP/15110020, Santiago, Chile \\ SEBASTIÁN ViCUÑA \\ Departamento de Ingeniería Hidráulica y Ambiental, and Centro Interdisciplinario de Cambio Global, Pontificia \\ Universidad Católica de Chile, and Centro Nacional de Investigación para la Gestión Integrada de Desastres \\ Naturales, CONICYT/FONDAP/15110017, Santiago, Chile
}

FRANCISCO MEZA

Centro Interdisciplinario de Cambio Global, and Facultad de Agronomía e Ingeniería Forestal, Pontificia Universidad Católica de Chile, Santiago, Chile.

(Manuscript received 10 January 2019, in final form 5 June 2019)

\begin{abstract}
The time at which climate change signal can be clearly distinguished from noise is known as time of emergence (ToE) and is typically detected by a general circulation model (GCM) signal-to-noise ratio exceeding a certain threshold. ToE is commonly estimated at large scales from GCMs, although management decisions and adaptation strategies are implemented locally. This paper proposes a methodology to estimate ToE for both precipitation and temperature at local scales (i.e., river basin). The methodology considers local climatic conditions and unbiased GCM projections to estimate ToE by using the statistical power to find when the climate significantly differs from the historical one. The method suggests that ToE for temperature already occurred in three Chilean basins (Limarí, Maipo, and Maule). However, in terms of precipitation, an earlier ToE is clearly identified for the Maule basin, indicating that risk assessment and adaptation measures should be implemented first in this basin.
\end{abstract}

\section{Introduction}

Hawkins and Sutton (2012) define time of emergence (ToE) as the time at which the signal of climate change emerges from the noise of natural variability. ToE studies not only focus on precipitation (Giorgi and $\mathrm{Bi}$ 2009; Hawkins and Sutton 2011; Lee et al. 2016; Nguyen et al. 2018) and temperature (Diffenbaugh and Scherer 2011; Hawkins and Sutton 2012; Mahlstein et al. 2011; Mora et al. 2013), but also heat waves and extreme

Corresponding author: Cristián Chadwick, cristian.chadwick@ uchile.cl temperatures (Harrington et al. 2016; King et al. 2015; King et al. 2016; Lopez et al. 2018), sea level (Carson et al. 2016; Lyu et al. 2014), current system upwelling (Brady et al. 2017), and different ocean properties (Keller et al. 2014; Henson et al. 2017). Finding ToE is relevant as it serves as a marker of human-induced climate change. Recent studies also mention its importance for decision-making, especially when implementing adaptation and mitigation plans (Nguyen et al. 2018; Zhou et al. 2018).

ToE is most commonly detected by a general circulation model (GCM) signal-to-noise ratio exceeding a certain threshold (Giorgi and Bi 2009; Hawkins and 
Sutton 2012; Keller et al. 2014; Lee et al. 2016; Lyu et al. 2014; Sui et al. 2014), although other alternatives have been proposed. For example, Muir et al. (2013) find the time at which the signal permanently exceeds the preindustrial simulated control variability. Other studies detect significant difference in climate using the Kolmogorov-Smirnov (KS) test (King et al. 2015; Mahlstein et al. 2011, 2012a,b; Leng et al. 2016; Zhou et al. 2018), although the statistical power of the test is neither reported nor used to identify the ToE year with a given probability.

A vast majority of studies estimate $\mathrm{ToE}$ at global scales (Giorgi and Bi 2009; Hawkins and Sutton 2012), or at large scales including China (Sui et al. 2014) and India (Akhter et al. 2018), with maps showing the local impacts at a broad scale. However, management decisions and adaptation strategies are implemented locally (for instance at the river basin scale), where climate variability can differ considerably from that of the GCM projections. A few studies have focused on a local characterization and identification of the ToE. The initiative CIG-Time of Emergence (http://toe.cig.uw.edu; University of Washington 2014) uses the Variable Infiltration Capacity (VIC) model (Liang et al. 1994, 1996) to determine the ToE for 35 climatic variables for different counties, watersheds, and major rivers of the Pacific Northwest in the United States. Furthermore, Leng et al. (2016) analyzed streamflow projections from VIC driven by 97 downscaled and bias-corrected CIMP5 climate projections over the conterminous United States (Bureau of Reclamation 2014) to estimate ToE for streamflows in different river basins. Using the approach proposed by Leng et al. (2016), Zhou et al. (2018) identified ToE in natural and regulated river flow regimes across the western United States, in order to understand regional differences and the potential relationship with the level of water management. Finally, Zhuan et al. (2018) proposed a method to estimate ToE at a local scale for hydrological impact studies in a Chinese basin, based on a multimember ensemble of a climate model. Because all these studies were developed in the Northern Hemisphere, particularly in the United States and China, local hydroclimate ToE for Latin America are yet to be estimated.

Moreover, a probabilistic approach in the identification of ToE is needed to incorporate its uncertainty in decision-making. However, dealing with this uncertainty has been a difficult and challenging task, and no general consensus on how to address the issue exists. For example, Hawkins et al. (2014) pointed out a possible underestimation of the uncertainty estimate in the early ToE identified by Mora et al. (2013). In one of the first ToE studies, Hawkins and Sutton (2011) identified the uncertainty related to internal variability, the model uncertainty and the scenario uncertainty, and calculated their relative contribution to the noise around the climate change signal. King et al. (2015) estimated the uncertainty by running individually 23 GCMs to identify the ToE and compared the results. Sui et al. (2014) also uses individual GCM runs to estimate the possible ToE range, by seasons in different regions of China. Lehner et al. (2017) analyze different sources of uncertainty and demonstrated that GCM biases in variability significantly impact ToE detection. Few studies have incorporated these biases to estimate ToE, mostly by using a quantile mapping bias correction (QM; Akhter et al. 2018; Leng et al. 2016; Bureau of Reclamation 2014; Zhou et al. 2018; Zhuan et al. 2018). Because QM can change the GCM trend and produce an effect comparable to other sources of uncertainty such as variability among GCMs (Maraun 2013; Pierce et al. 2013), a procedure for unbiased mapping of GCMs changes to local stations should be evaluated and eventually used in the detection of ToE.

Overall, two relevant issues remain to be better addressed in the identification of ToE: 1) accounting for GCM biases in variability by considering both local climatic conditions and GCM projections to identify the ToE at local scales (i.e., river basin) and 2) determining the probability of certainty of this identification. The objective of this paper is to propose a methodology to identify the ToE for annual precipitation and temperature that addresses both issues abovementioned. The proposed methodology identifies ToE at a local scale and relies on the calculation of the statistical power to identify significant differences between climate series with natural variability and series that also incorporate GCM trend percentiles. We evaluated the methodology on the Southern Hemisphere Pacific coast, by using three Chilean river basins under four representative concentration pathway (RCP) scenarios.

\section{Methodology}

To identify the ToE for precipitation and temperature at a local scale (i.e., meteorological gauge) without significant bias, either a dynamical or statistical downscaling and/or bias correction method is required. Statistical methods are more computationally efficient and include regression models, weather typing schemes, and weather generators (Wilby and Wigley 1997; Fowler et al. 2007). In this study, we adopt the weather generator downscaling method proposed by Chadwick et al. (2018), which ensures the preservation of the GCMs trends when generating climate series at the local scale. However, prior to implementing the method, the inverse distance weighting 

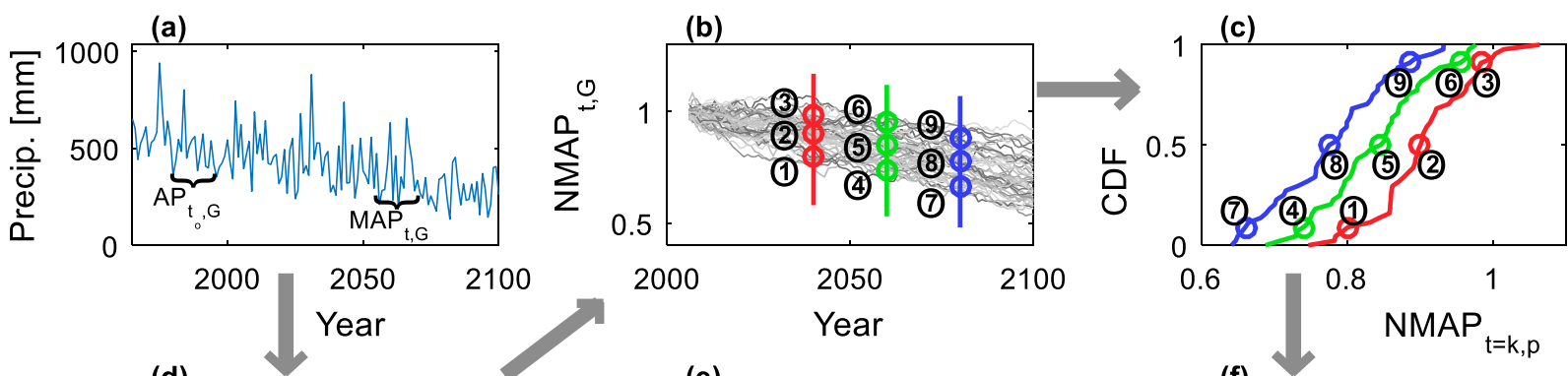

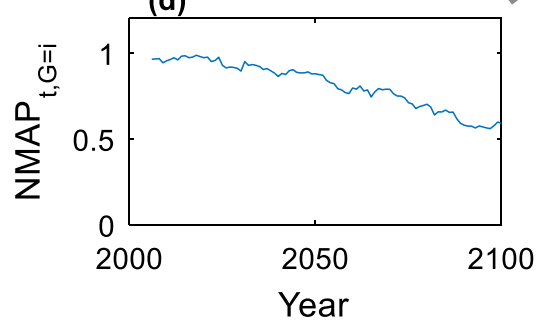

(g)

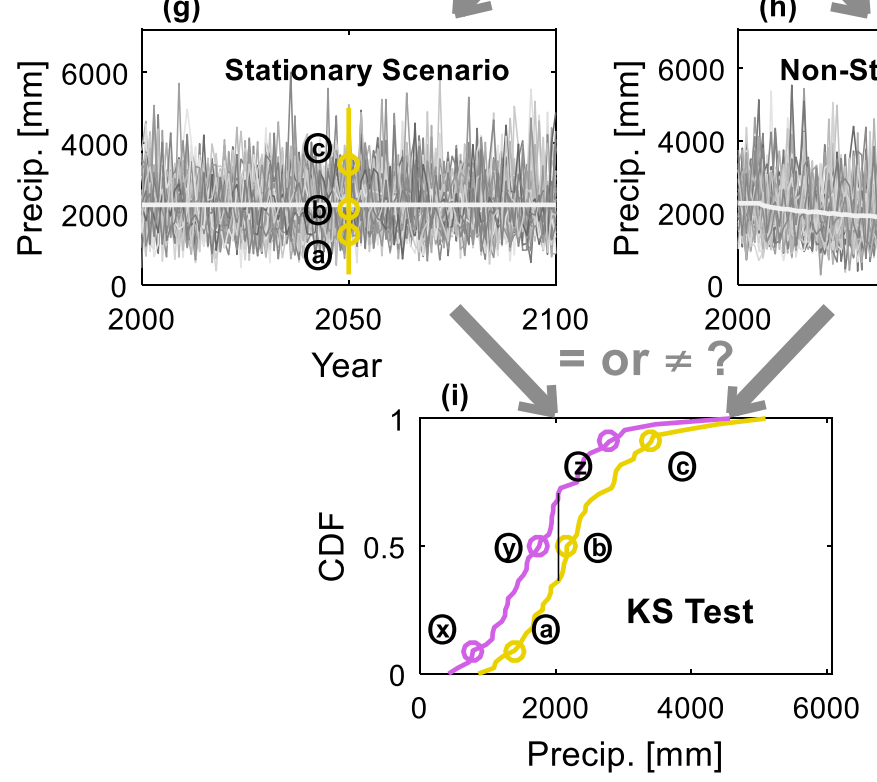

(e)

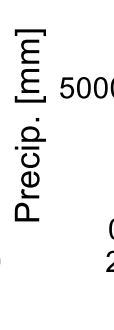

(h)
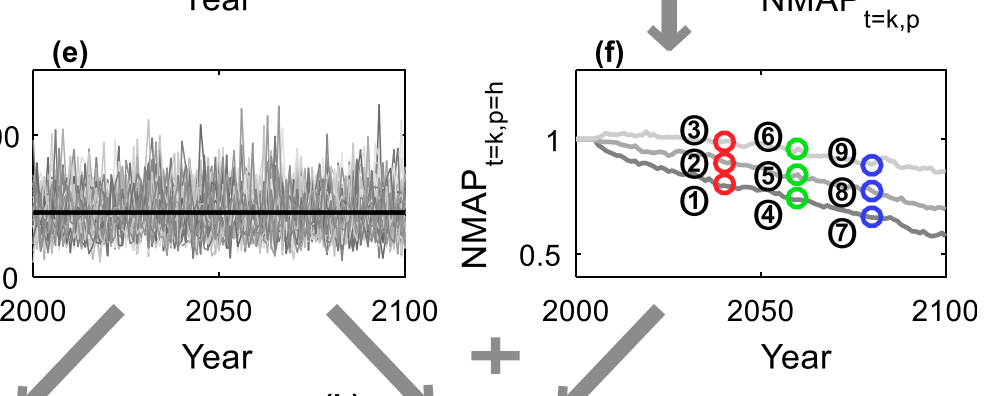
normalized moving average $\left(\mathrm{NMAP}_{t, G} ;\right.$ Fig. $\left.1 \mathrm{~d}\right)$. The trends are built using all the $\mathrm{NMAP}_{t, G}$ from each RCP (Fig. 1b). For each year $t$ an empirical cumulative distribution function $(\mathrm{CDF})$ of all the $\mathrm{NMAP}_{t, G}$ is fitted (Fig. 1c). Finally, the trend percentile with a nonexceedance probability $p_{1}, \mathrm{NMAP}_{t, p 1}$, is obtained from the CDFs of each year (Fig. 1f). Note that $\mathrm{NMAP}_{t, p_{1}}$ corresponds to a statistical mapping of the changes from a GCM group, and several trend percentiles can be used to map the dispersion among the group of GCM results.

An analogous process is undertaken for the standard deviation of precipitation from the GCM group. In this case, the method defines a normalized moving standard deviation $\left(\mathrm{NMSDP}_{t, G}\right)$ for each GCM projection $G$, which corresponds to the ratio between the GCM precipitation output moving standard deviation $\left(\mathrm{MSDP}_{t, G}\right)$ and the standard deviation from the control period $\left(\mathrm{SDP}_{t_{o}, G}\right)$. Just as for the precipitation mean, for each year $t$ a CDF of all the $\operatorname{MSDP}_{t, G}$ is fitted and a trend percentile with a nonexceedance probability $p_{2}$ can be obtained from the CDFs of each year. However, $p_{2}$ is randomly generated considering the average correlation with the chosen trend percentile $p_{1}$ of the mean, as recommended by Chadwick et al. (2018). For temperature, a similar process for extracting the trends is applied; these trends however are built with the difference between the moving average of the temperatures and the average temperature of the control period of the GCM.

For the generation of annual climate series of data (Fig. 1e), in each station of interest probability distribution functions (PDFs) $f_{Y}(y, \theta)$ are fitted to the observed annual records of the variable $Y$ (temperature or precipitation) through the estimation of the parameter set $\theta$ using the mean $\mu$ and standard deviation $\sigma$. These PDFs are used to generate stationary time series of precipitation and temperature (Fig. 1g):

$$
Y_{t, i}=F_{Y}^{-1}(u, \theta)=F_{Y}^{-1}(u, \mu, \sigma),
$$

where $u$ is a random uniform number $[0,1]$, and $Y_{i, t}$ is the $i$ th stationary annual precipitation or temperature value randomly generated for the year $t$.

A second set of annual climate data combines the GCMs trend percentiles and the local climate PDFs $f_{Y}(y, \theta)$ (Fig. 1h), case in which the parameter set $\theta$ change in time according to the GCMs. Hence, this set is a GCM ensemble that incorporates the natural variability. Under this approach, the value of the climatic variable at any time for a given $p_{1}$ and RCP is the value obtained from the PDF, but with mean $\mu^{*}$ and standard deviation $\sigma^{*}$ that change through time according to the trends:

$$
Y_{t, i, p_{1}}=F_{Y}^{-1}(u, \theta)=F_{Y}^{-1}\left[u, \mu^{*}\left(t, p_{1}\right), \sigma^{*}\left(t, p_{2}\right)\right],
$$

where $Y_{t, i, p_{1}}$ is the $i$ th annual precipitation or temperature value randomly generated, using the trend percentile $p_{1}$ of the mean, for the nonstationary set of climate. The value of $\mu^{*}$ and $\sigma^{*}$ in Eq. (2) at any particular year $t$ for precipitation are calculated from the historical mean $\mu$ and standard deviation $\sigma$ and the multiplicative normalized change rates:

$$
\begin{aligned}
& \mu^{*}\left(t, p_{1}\right)=\mu \operatorname{NMAP}_{t, p_{1}}, \\
& \sigma^{*}\left(t, p_{2}\right)=\sigma \mathrm{NMSDP}_{t, p_{2}} .
\end{aligned}
$$

For temperature, $\mu^{*}$ and $\sigma^{*}$ are obtained using the additive changes rates:

$$
\begin{aligned}
& \mu^{*}\left(t, p_{1}\right)=\mu+\mathrm{DMAT}_{t, p_{1}}, \\
& \sigma^{*}\left(t, p_{2}\right)=\sigma+\mathrm{DMSDT}_{t, p_{2}} .
\end{aligned}
$$

For a more detail description of the climate time series generation method, the reader is referred to the paper by Chadwick et al. (2018).

\section{b. Identifying the ToE}

To identify ToE, we used the KS test to reject (or not) the null hypothesis $H_{o}$ that the two sets of climate data generated for each year belong to the same population (Fig. 1i). A value of 1 is assigned if the hypothesis is rejected and 0 otherwise:

$$
\mathrm{KS}_{t, j}= \begin{cases}1, & \text { if } H_{o} \text { is rejected } \\ 0, & \text { if } H_{o} \text { is not rejected }\end{cases}
$$

where $\mathrm{KS}_{t, j}$ is the result of the hypothesis test for year $t$ of the repetition $j$ of the test, from a total number of $R$ repetitions. Thus, the ToE corresponds to the year when the GCM trend makes the two sets of climate generated with Eqs. (1) and (2) significantly different. Such difference is assessed by means of the statistical power (hereafter denoted power, $W$ ) of the KS test (i.e., the probability of rejecting the null hypothesis when the alternative hypothesis $H_{1}$ that the two sets of climate data come from different populations is correct):

$$
W=1-\beta=\frac{\sum_{j=1}^{R} \mathrm{KS}_{t, j}}{R},
$$

where the power $W=1-\beta$ is empirically estimated as the percentage of time the hypothesis $H_{o}$ is rejected. A mean power larger than a threshold value $K($ e.g., $K=0.6)$ 

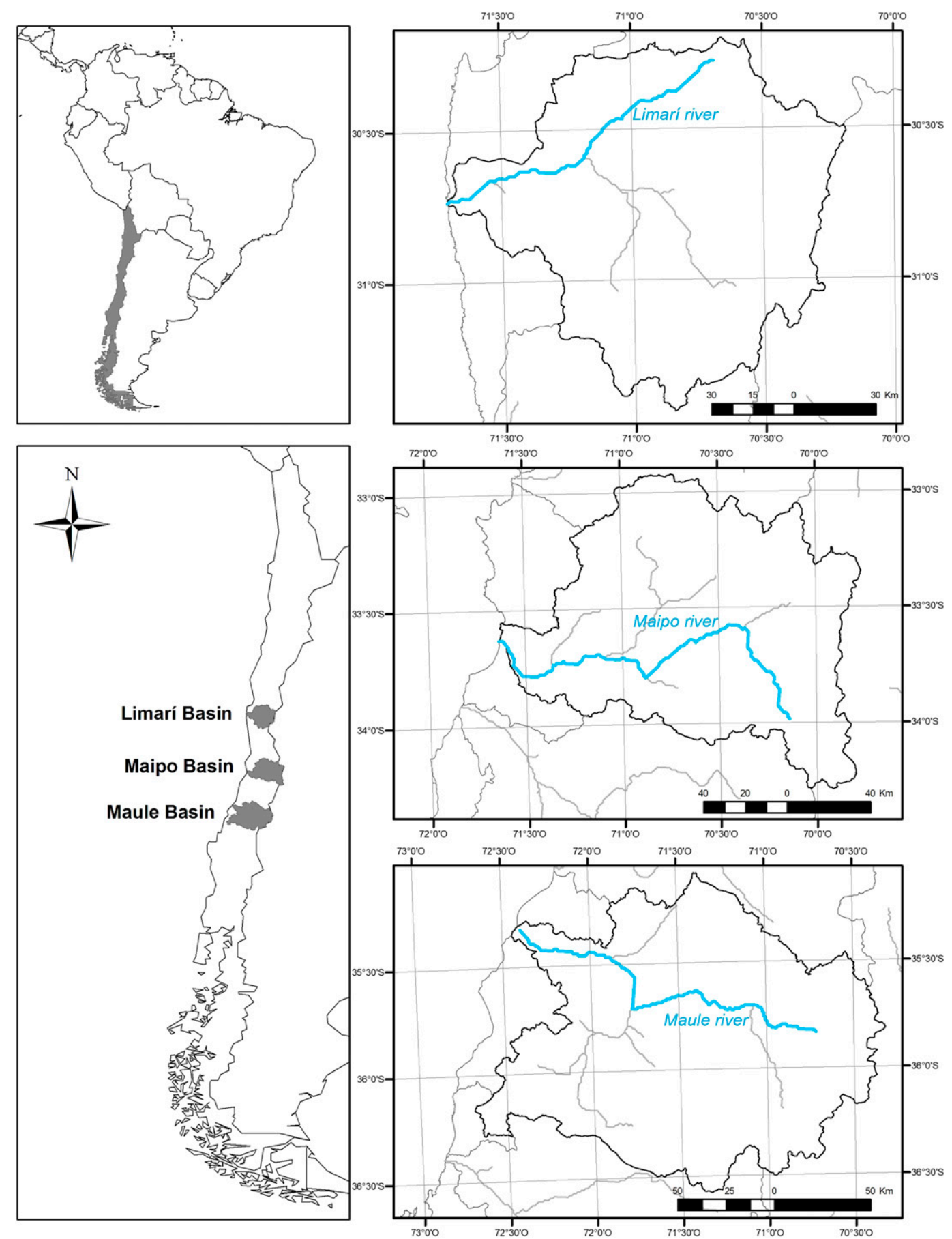

FIG. 2. Case study basins and their locations in central Chile.

implies the identification of the ToE with probability $K$ of making the correct assessment.

To reduce computational time and obtain the power from several KS tests, a bootstrapping approach is implemented. According to the approach, $N_{1}$ annual climate series of precipitation and temperature are produced for the stationary climate conditions using
Eq. (1), and for each of the GCM trend percentiles using Eq. (2). Thus, for the stationary climate and for a given trend percentile there are $N_{1}$ annual values of precipitation and temperature, with $N_{1}$ being a large number, initially 3000 . Through the bootstrapping, $R$ samples of size $N_{2}$ are randomly selected from each set of generated climate, for which the KS test is applied with a 
TABLE 1. Study river basins and information about mean and standard deviation of precipitation $(\mathrm{mm})$ and temperature $\left({ }^{\circ} \mathrm{C}\right)$, and precipitation CV in representative gauges, for the time period 1978-2005.

\begin{tabular}{llcccccccc}
\hline \hline & & & & & & \multicolumn{2}{c}{ Precipitation } & \multicolumn{2}{c}{ Temperature } \\
\cline { 6 - 9 } Basin & Gauge & Latitude & Longitude & Elevation $(\mathrm{m})$ & Mean & Std dev & CV & Mean & Std dev \\
\hline Limarí & Las Ramadas & $31^{\circ} 01^{\prime} 11^{\prime \prime} \mathrm{S}$ & $70^{\circ} 35^{\prime} 11^{\prime \prime} \mathrm{W}$ & 1380 & 341.5 & 209.8 & 0.61 & 16.3 \\
Maipo & Cerro Calán & $33^{\circ} 23^{\prime} 42^{\prime \prime} \mathrm{S}$ & $70^{\circ} 32^{\prime} 12^{\prime \prime} \mathrm{W}$ & 848 & 452.2 & 201.0 & 0.54 \\
Maule & Armerillo & $35^{\circ} 42^{\prime} 04^{\prime \prime} \mathrm{S}$ & $71^{\circ} 04^{\prime} 38^{\prime \prime} \mathrm{W}$ & 492 & 2397.2 & 807.2 & 0.34 & 16.3 & 0.40 \\
\hline
\end{tabular}

significance level $\alpha=1 \%$. A value of $N_{2}=1062.76 \approx 1000$ is determined by restricting the maximum difference between the cumulative distribution function of the two sets of climate data to 0.05 (i.e., $d_{0.01}=1.63 / \sqrt{N_{2}}=0.05$ ) (Massey 1951), whereas $R=100$ to obtain a power value with two significant digits. Hence, over two repetitions, only $N_{2} / N_{1}=1 / 3$ of the sample size is expected to be repeated. Nonetheless, a sensitivity analysis evaluating different values of $\alpha, N_{1}, N_{2}$, and $R$ is presented in the results section.

\section{Study area and climate series}

The methodology was applied to three Mediterranean basins in central Chile, ranging from semiarid to humid (Fig. 2): the Limarí, the Maipo, and the Maule river basins. These basins have the Pacific Ocean to the west and the Andes Mountains to the east, and average precipitation values of 341,452 , and $2397 \mathrm{~mm}$ are recorded, respectively, in the gauges selected for each basin (Table 1). In this area while annual rainfall increases from north to south, temperature decreases. Conversely, the values of the coefficient of variation $(\mathrm{CV})$ reflect a decreasing interannual precipitation with latitude, having values of $0.61,0.44$, and 0.34 for Limarí, Maipo, and Maule, respectively. The three study basins present a high variability anomaly as studied by Sokol Jurković and Pasaric (2013), which explains the high CV values. The historical record used (i.e., period from 1978 to 2005) is restricted on one side by the year 1978 to avoid the effect of a shift in the Pacific decadal oscillation that occurred between 1975 and 1976 (Boisier and Aceituno 2006; Bown and Rivera 2007; Giese et al. 2002; Rosenblüth et al. 1997; Trenberth 1990; Trenberth and Stepaniak 2001) and, on the other end, by the year 2005, the final year of the historical simulation period of the GCMs (Taylor et al. 2012).

We considered 49 realizations of $20 \mathrm{GCMs}$, resulting in 149 combinations of different GCMs and RCP scenarios 2.6, 4.5, 6.0, and 8.5 (Moss et al. 2010), from phase 5 of the Coupled Model Intercomparison Project (CMIP5; Taylor et al. 2012). Because each one of the GCMs was assumed to have the same weight, the inverse of the number of realizations of each GCM is used as weighting factor for each one of the GCM projections (Chadwick et al. 2018). Table A1 shows all the GCMs and RCPs combinations used in this study.

Chadwick et al. (2018) applied their time series generator method to explore the expected future climate in the study basins under study. Under the RCP8.5 scenario, average temperature is expected to increase by 2100 around $4.2^{\circ}, 3.8^{\circ}$, and $3.6^{\circ} \mathrm{C}$ for the Limarí, Maipo, and Maule basins, respectively. Annual precipitation is expected to significantly decrease, with average reductions of $24.0 \%, 27.5 \%$, and $29.4 \%$ being estimated for the gauges located in the same basins by 2100 under the RCP8.5 scenario. These precipitation reductions are so severe that the probability of observing three consecutive years with precipitation under the historical mean in these three basins is expected to increase by the year 2090 from $23 \%$ to $49 \%$ in Limarí, from $24 \%$ to $54 \%$ in Maipo, and from $20 \%$ to $59 \%$ in Maule. For more detail about the expected changes in temperature and precipitation for the study basins, the reader is referred to the work by Chadwick et al. (2018).

\section{Results and discussion}

\section{a. Time of emergence}

The KS test power values for precipitation and temperature for the three study basins are shown in Figs. 3 and 4 , respectively. In both figures the values are presented for each year under RCPs 2.6 (first row), 4.5 (second row), 6.0 (third row), and 8.5 (fourth row). We used 19 trend percentiles of the mean (5th, 10th, ..., 95th) to characterize the GCM uncertainty ( $y$ axis). Black lines indicate the transition zone of the ToE, identifying the first and last year with power of 0.25 and 0.75 for the 25 th, 50 th, and 75 th percentiles of the GCM trends. If the 0.75 threshold is never exceeded during the entire period, the transition zone is assumed to go beyond 2100 .

For the three basins under RCP2.6, the end of the transition zone for the precipitation ToE when considering the 50th trend percentile is close to or later than 2100 (Fig. 3, first row). For higher trend percentiles, the transition's end occurs after 2100 , except on the Limarí 
(a)

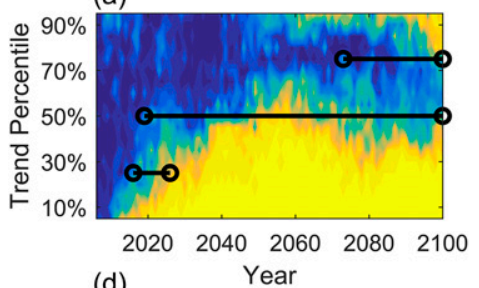

(d)

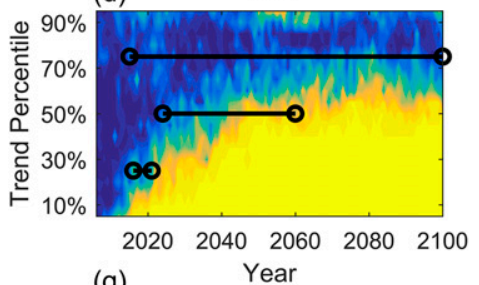

(g)

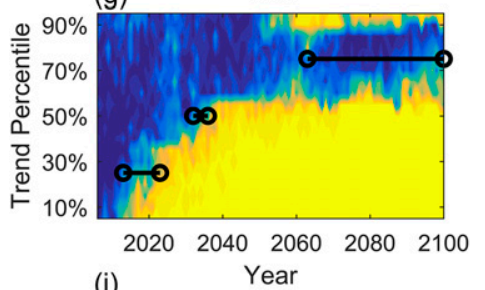

(j)

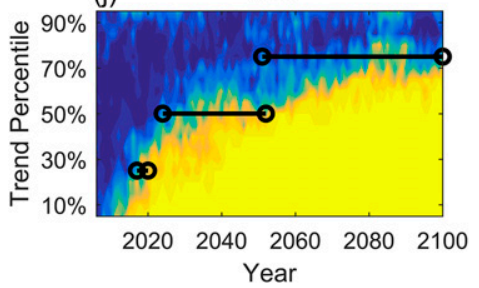

(b)

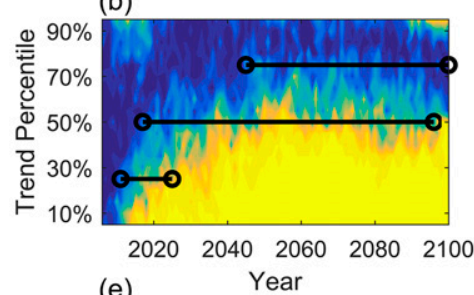

(e)

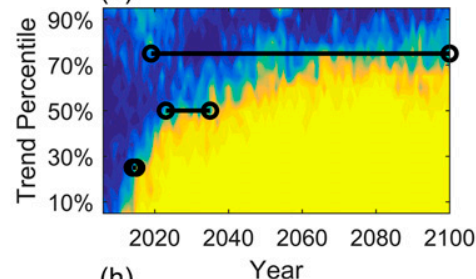

(h)

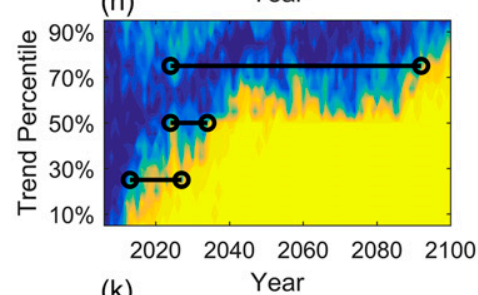

(k)

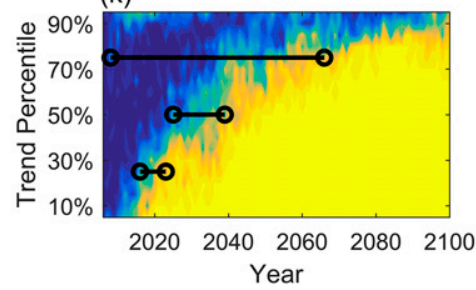

(c)

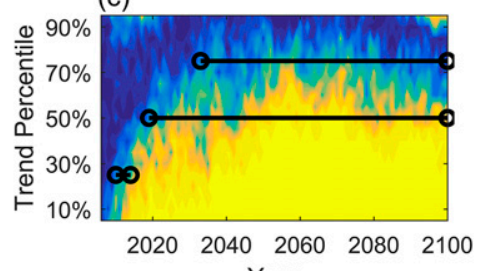

(f)

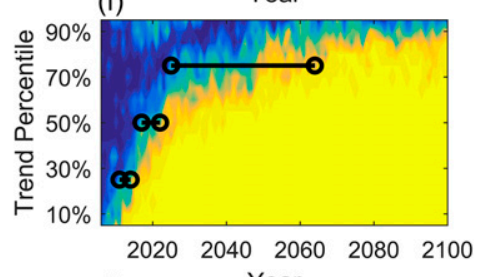

(i)

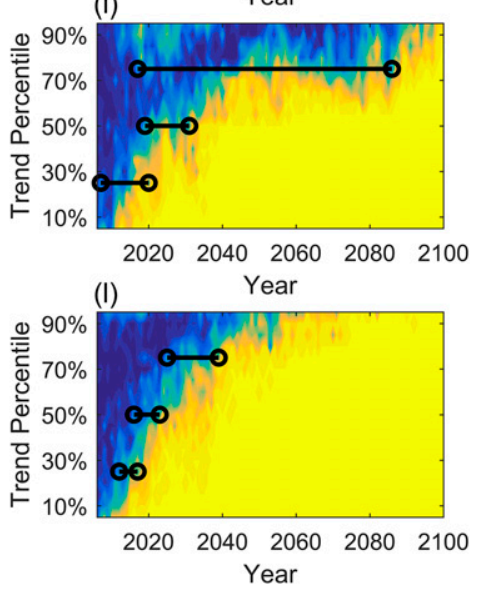

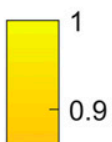

0.8

0.7

0.6

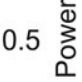

0.4

0.3

0.2

0.1

FIG. 3. Power of the KS test resulting over time and for different GCM trend percentiles of the mean, which represent the ToE of precipitation for the (left) Limarí, (center) Maipo, and (right) Maule basins under (a)-(c) RCP2.6, (d)-(f) RCP4.5, (g)-(i) RCP6.0, and (j)-(l) RCP8.5. Black lines indicate the first and last year with power of 0.25 and 0.75 for the GCM 25th, 50th, and 75 th percentiles.

basin (Fig. 3a), in which there are large power values associated with high trend percentiles that are related to precipitation increases by the end of the century. Under RCP4.5, changes in precipitation above the 60th and 70th trend percentiles do not emerge by 2100 in the Limarí (Fig. 3d) and the Maipo basin (Fig. 3e) respectively, whereas for the Maule basin (i.e., the basin with the least interannual precipitation variability) the change in precipitation emergences before 2100 for almost the totality of the GCMs (Fig. 3f). Under RCP6.0, changes in precipitation for approximately $20 \%$ and $10 \%$ of the GCMs do not emerge by 2100 in the Limari (Fig. 3g) and the Maipo basin (Fig. 3h) respectively, whereas for the Maule basin the ToE takes place before 2100 for all the GCMs (Fig. 3i). As in the case of the scenario RCP2.6, in the Limarí basin the ToE is identified before 2100 for the highest percentiles of precipitation due to a few of the GCM projections predicting increasing precipitation, as opposed to the reduction predicted by most of the GCMs (Fig. 3g). Under RCP8.5 the ToE for precipitation has not completely emerged by 2100 only for the Limarí basin (Fig. 3j), as the last computed ToE occurs close to 2100 in the Maipo basin (Fig. 3k), and between the years 2050 and 2060 in the Maule basin (Fig. 31).

Regardless of the RCP and the basin, different trend percentiles have significantly different associated ToE values. For example, if a power of 0.75 is used to detect ToE, a delay of more than 40 years is observed when comparing the 75th and 25th GCM trend percentiles, except for the Maule basin under RCP8.5 (Fig. 31). Under RCPs 2.6 and 6.0 the ToE associated with a power of 0.75 delays more than 60 years when considering the 75th trend percentile instead of the 25th one, for the three basins. Under RCP8.5, the trend percentile impacts considerably the ToE identification, although the spatial location also plays a significant role. Indeed, the ToE associated with a power of 0.75 delays more than 80 years for the Limarí basin when comparing the 25 th and 75 th percentile, delay that is reduced to 
(a)
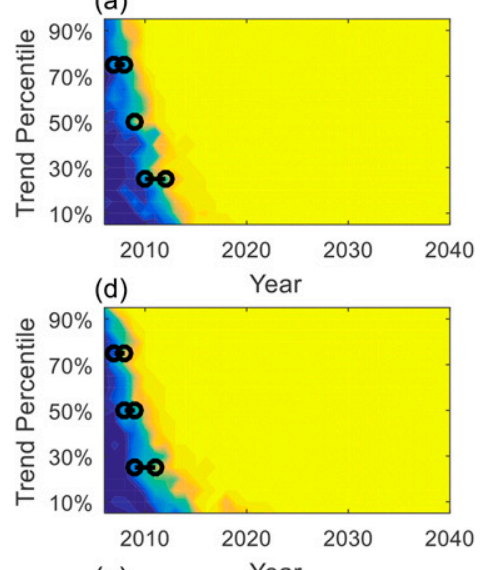

(g)
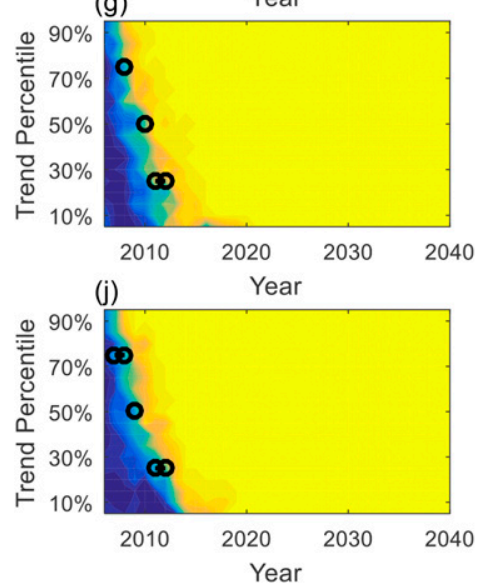

(b)

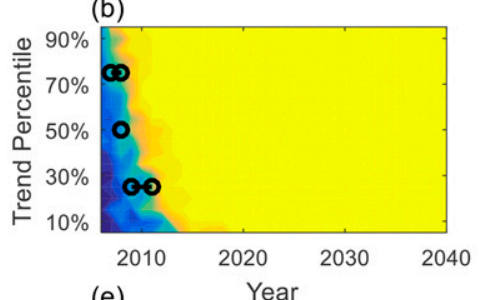

(e)

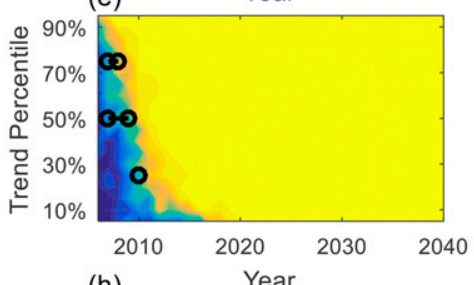

(h)

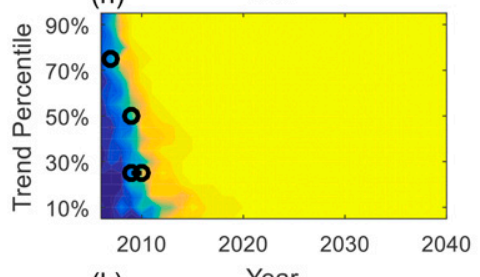

(k)

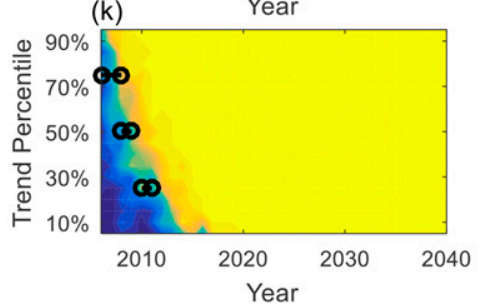

(c)
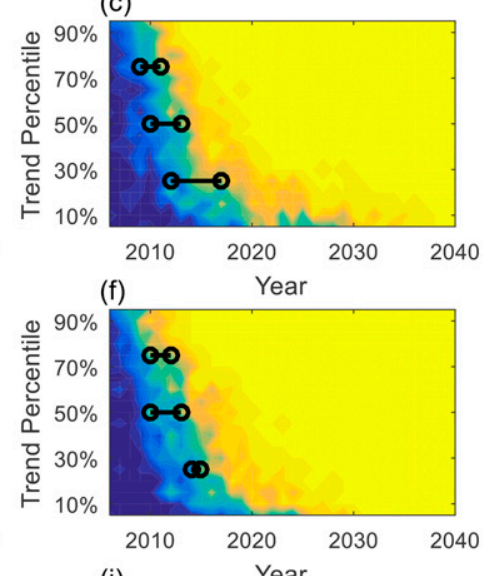

(i)
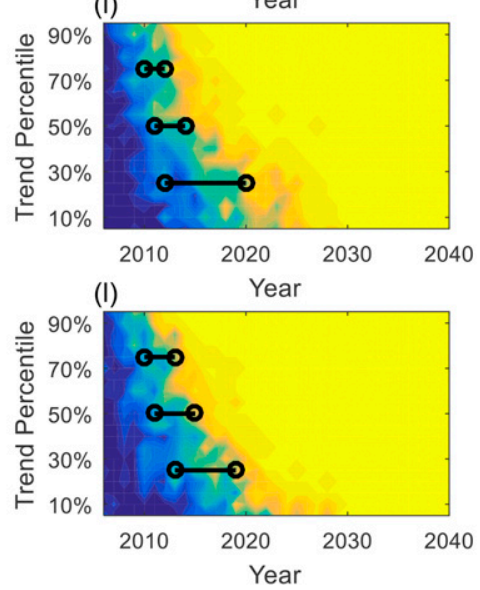

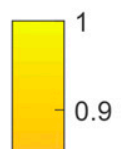

0.8

$-0.7$

0.6

$0.5 \sum_{0}^{\infty}$

0.4

0.3

0.2

0.1

FIG. 4. Power of the KS test resulting over time and for different GCM trend percentiles of the mean, which represent the ToE of temperature for the (left) Limarí, (center) Maipo, and (right) Maule basins under (a)-(c) RCP2.6, (d)-(f) RCP4.5, (g)-(i) RCP6.0, and (j)-(1) RCP8.5. Black lines indicate the first and last year with power of 0.25 and 0.75 for the GCM 25th, 50th, and 75 th percentiles.

$\sim 20$ years for the Maule basin. This difference among basins is most likely due to their different $\mathrm{CV}$ values (Table 1). Shorter transitions, of 10 years or less, tend to be associated with the GCMs predicting higher precipitation reductions (below 30th percentile). Overall, the basin with the shortest transition zone is the Maule river basin (Fig. 3, third column).

The transition zone for temperature occurs before 2020 for the three basins under the four RCPs (Fig. 4). Moreover, after 2030 there is a complete certainty (i.e., power of 1) that temperature differs from the historical one for all the GCMs in all the basins, with the ToE of the Maule basin being the last one. Furthermore, the impact of the trend percentile over ToE for temperature is much smaller than that for precipitation.

Figure 5 shows the annual average power values for each basin and RCP, which combine the 19 trend percentiles. This figure can be used as a reference to compare the expected ToE among different study basins, to communicate in a simple way the results to decision makers, stakeholders and the general public, or to plan adaptation strategies at early stages. However, Fig. 5 must be treated carefully as the identification of ToE from the average power can lead to a wrong perception of certainty.

For all the RCPs, the ToE of precipitation (Figs. 5a-d) occurs first in the Maule basin (dotted blue line) and last in the Limarí basin (solid red line). If 0.6 is adopted as the threshold power value, under RCP2.6 the ToE of precipitation would occur in years 2049, 2038, and 2028 for the Limarí, Maipo, and Maule basins, respectively (Fig. 5a), while under RCP8.5, these years are 2034, 2038, and 2024 (Fig. 5d). A power of 0.9 is never reached in any of the three basins under RCP2.6 (Fig. 5a), while only in the Maule basin a power value of 0.9 is reached under RCP4.5 (Fig. 5b). By 2100, the Maule basin is the only one with a power value of 1 under RCP6.0 (Fig. 5c), while under RCP8.5 a power of 1 is reached in the Maule and the Maipo basins by years 2070 and 2100, respectively (Fig. 5d). Limarí is the only basin in which under 

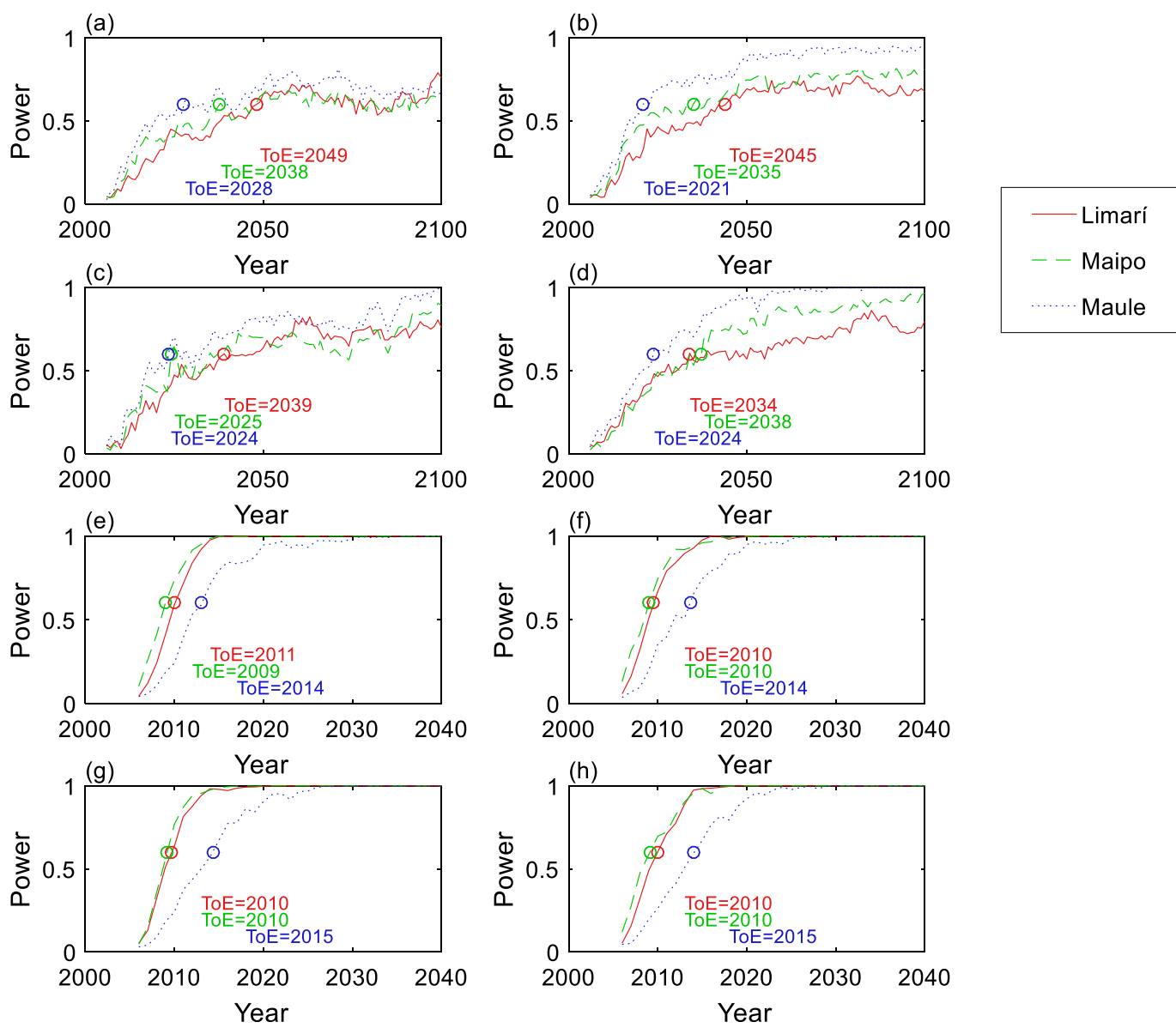

FIG. 5. Average power trough time representing the ToE of (a)-(d) precipitation and (e)-(h) temperature for the Limarí, Maipo, and Maule basins under RCP2.6 in (a) and (e); RCP4.5 in (b) and (f); RCP6.0 in (c) and (g); and RCP8.5 in (d) and (h). The circle marker indicates the ToE associated with a power of 0.6.

the four RCPs, a power value of 0.9 is not reached. Overall, for more pessimistic RCP scenarios ToE occurs earlier with a greater degree of certainty. Nevertheless, the GCM signal is similar for the three basins, so the GCM signal is likely not the largest source of differences among the basins, but the local climate variability, which is captured by the climate generator method used in the study.

ToE for temperature occurs at the beginning of the century regardless of the RCP or basin (Figs. 5e-h). By the year 2020 both in the Limarí and Maipo basins power values of 1 are reached for temperature regardless the RCP, whereas in the Maule basin power values of 1 for temperature are reached by year 2025 under all four RCPs. These results suggest that temperature changes significantly for all the GCMs and RCPs.

The ToE values presented in Fig. 5 correspond to a simplified version of the full range of ToE values presented in Figs. 3 and 4. For example, no significant differences between historical and future precipitation are observed for several trend percentiles (i.e., between the 65th and 80th trend percentile) in the Limarí basin, regardless the RCP scenario (Fig. 3, first column). However, using the mean power to estimate the ToE may give the wrong interpretation that the climate will definitively change in the basin (Fig. 5). Also, using the average trend may lead to identify the ToE of precipitation before 2060 for the three basins under RCPs 4.5, 6.0, and 8.5, while for higher trend percentiles the ToE can occur later, or not even within this century.

\section{b. Sensitivity analysis}

An analysis was performed to study the sensitivity of the transition zone (i.e., first and last year with power of 0.25 and 0.75 ) to changes in the parameter's values involved in the proposed approach (i.e., $N_{1}, N_{2}, R$, and $\alpha$ ). The analysis is performed for precipitation in the Maipo basin under RCP8.5, although the results are similar for the other basins and RCPs. Changing $N_{1}$ does not have a clear impact on the ToE year (Table 2), while the ToE is 
TABLE 2. Sensitivity analysis of the first and last years in the transition zone (i.e., power of 0.25 and 0.75 ), for the precipitation in the Maipo basin under RCP8.5. Parameters used in section 4a are in bold.

\begin{tabular}{|c|c|c|c|c|c|c|}
\hline \multirow[b]{2}{*}{ Power } & \multicolumn{6}{|c|}{ Total size $\left(N_{1}\right)$} \\
\hline & 1500 & 3000 & 5000 & 8000 & 12000 & 17000 \\
\hline 0.25 & 2014 & 2016 & 2016 & 2016 & 2017 & 2016 \\
\hline \multirow[t]{2}{*}{0.75} & 2044 & 2042 & 2043 & 2042 & 2045 & 2044 \\
\hline & \multicolumn{6}{|c|}{ Sample size $\left(N_{2}\right)$} \\
\hline Power & 50 & 100 & 250 & 500 & 1000 & 2000 \\
\hline 0.25 & 2059 & 2048 & 2032 & 2022 & 2016 & 2010 \\
\hline \multirow[t]{2}{*}{0.75} & $>2100$ & $>2100$ & 2085 & 2059 & 2043 & 2031 \\
\hline & \multicolumn{6}{|c|}{ Number of repetitions $(R)$} \\
\hline Power & 25 & 50 & 100 & 250 & 500 & 1000 \\
\hline 0.25 & 2016 & 2016 & 2016 & 2015 & 2016 & 2015 \\
\hline \multirow[t]{2}{*}{0.75} & 2044 & 2043 & 2046 & 2040 & 2045 & 2040 \\
\hline & \multicolumn{6}{|c|}{ Level of significance $(\alpha)$} \\
\hline Power & $1 \%$ & $2 \%$ & $3.5 \%$ & $5 \%$ & $7.5 \%$ & $10 \%$ \\
\hline 0.25 & 2016 & 2013 & 2012 & 2011 & 2008 & 2007 \\
\hline 0.75 & 2047 & 2041 & 2035 & 2035 & 2032 & 2031 \\
\hline
\end{tabular}

detected sooner when increasing $N_{2}$. Furthermore, $R$ does not impact the results, although a minimum number of repetitions is required for the identification power values with two decimal places. Last, as expected, increasing $\alpha$ reduces the ToE year. In fact, as $\alpha$ and, to a larger extent, $N_{2}$, affect the results by changing the value of the KS test statistic, they must be selected carefully. Overall, we emphasize the relevance of a sensitivity analysis like the one presented.

\section{Conclusions}

This work proposes a method to detect the time of emergence (ToE) of climate change at a basin scale using trend percentiles of the GCMs projections and local climate information. By means of the statistical power, the method identifies differences between stationary historical climate and the nonstationary local climate generated using these projections. The method was applied to detect ToE of annual precipitation and temperatures in three Mediterranean basins in Chile, with climates ranging from semiarid to humid (i.e., the Limarí, Maipo, and Maule river basins). The following are our main conclusions.

- The ToE for precipitation takes place later for higher values of the local $\mathrm{CV}$. Thus, the climate change signal emerges from the local climate first in the Maule basin, and then in the Maipo and Limarí basins. On the other hand, the ToE for temperature pretty much already occurred in the three basins. Thus, local climate change impacts will be seen first in Maule basin, which should be considered when assessing risk and adaptation measures. Our ToE identification is consistent with studies reporting the recent megadrought in central Chile, which has been partly attributed to climate change (Boisier et al. 2016; Garreaud et al. 2017).

- The aforementioned relationship between ToE and $\mathrm{CV}$ among different locations may not hold for other cases, as the strength of the GCMs signal can also be relevant.

- The chosen GCM trend percentile significantly impacts the ToE detection. In fact, the ToE associated with a given power can be delayed in several decades when considering different GCM trend percentiles. Moreover, using the average or median of the trend percentile could lead to a false sense of certainty about changes in climate, when some GCMs do not predict significant changes (e.g., precipitation in the Limarí basin).

- As expected, the implementation of the statistical test to differentiate the future and stationary climate affects the ToE identification. The parameters impacting this implementation are those affecting the rejection or nonrejection of the KS test (i.e., the sample size and the level of significance $\alpha$ ).

- Overall, under a continuous change the emergence cannot be assigned to a single year, unless threshold values of those evolving metrics reflecting the climate dynamics are defined. Nevertheless, exceeding these values does never imply total certainty that the emergence takes place.

- Because it explicitly estimates the probability of occurrence of the ToE, the proposed method is an alternative to those proposed in the literature, which have quantified the uncertainty in the ToE estimation by using individually several GCMs (King et al. 2015; Sui et al. 2014). These methodologies produce a range of possible ToE values but not their probabilities of occurrence.

The proposed methodology enables the comparison of the ToE at different locations under a specific RCP scenario with an uncertainty assessment of a large group of GCMs. These estimations can be then used in the prioritization and implementation of local risk assessment and adaptation measures. Although the methodology was tested in a wide range of climates, its application over other climatic regions should be tested in the future. Furthermore, as the methodology works at an annual scale, one could use a monthly or weekly disaggregation method to identify $\mathrm{ToE}$ at finer time resolutions, although more uncertainty could be incorporated to the process given the lack of certainty on how the future intra-annual climate will be. Finally, 
TABLE A1. GCM and RCP scenarios used in this study. Note that the atmospheric horizontal grid is as reported in Flato et al. (2013).

\begin{tabular}{|c|c|c|c|c|c|c|c|}
\hline & GCM name & Realization & $\mathrm{RCP} 2.6$ & RCP4.5 & RCP6.0 & RCP8.5 & Atmosphere horizontal grid \\
\hline 1 & ACCESS1.0 & r1i1p1 & & $\mathrm{x}$ & & $\mathrm{x}$ & $192 \times 145$ N96 \\
\hline 2 & BCC-CSM1.1 & r1i1p1 & $\mathrm{x}$ & $\mathrm{x}$ & $\mathrm{x}$ & $\mathrm{x}$ & T42 T42L26 \\
\hline 3 & CanESM2 & r1i1p1 & $\mathrm{x}$ & $\mathrm{x}$ & & $\mathrm{x}$ & Spectral T63 \\
\hline 4 & CanESM2 & r2ilp1 & $\mathrm{x}$ & $\mathrm{x}$ & & $\mathrm{x}$ & Spectral T63 \\
\hline 5 & CanESM2 & r3i1p1 & $\mathrm{x}$ & $\mathrm{x}$ & & $\mathrm{x}$ & Spectral T63 \\
\hline 6 & CanESM2 & r4i1p1 & $\mathrm{x}$ & $\mathrm{x}$ & & $\mathrm{x}$ & Spectral T63 \\
\hline 7 & CanESM2 & r5ilp1 & $\mathrm{x}$ & $\mathrm{x}$ & & $\mathrm{x}$ & Spectral T63 \\
\hline 8 & CCSM4 & r1i1p1 & $\mathrm{x}$ & $\mathrm{x}$ & $\mathrm{x}$ & $\mathrm{x}$ & $0.9^{\circ} \times 1.25^{\circ}$ \\
\hline 9 & CCSM4 & r2i1p1 & $\mathrm{x}$ & $\mathrm{x}$ & $\mathrm{x}$ & $\mathrm{x}$ & $0.9^{\circ} \times 1.25^{\circ}$ \\
\hline 10 & CCSM4 & r3i1p1 & $\mathrm{x}$ & $\mathrm{x}$ & $\mathrm{x}$ & $\mathrm{x}$ & $0.9^{\circ} \times 1.25^{\circ}$ \\
\hline 11 & CCSM4 & r4i1p1 & $\mathrm{x}$ & $\mathrm{x}$ & $\mathrm{x}$ & $\mathrm{x}$ & $0.9^{\circ} \times 1.25^{\circ}$ \\
\hline 12 & CCSM4 & r5i1p1 & $\mathrm{x}$ & $\mathrm{x}$ & $\mathrm{x}$ & $\mathrm{x}$ & $0.9^{\circ} \times 1.25^{\circ}$ \\
\hline 13 & CNRM-CM5 & r10i1p1 & & & & $\mathrm{x}$ & TL127 \\
\hline 14 & CNRM-CM5 & r1i1p1 & & $\mathrm{x}$ & & $\mathrm{x}$ & TL127 \\
\hline 15 & CNRM-CM5 & r2i1p1 & & & & $\mathrm{x}$ & TL127 \\
\hline 16 & CNRM-CM5 & r4i1p1 & & & & $\mathrm{x}$ & TL127 \\
\hline 17 & CNRM-CM5 & r6i1p1 & & & & $\mathrm{x}$ & TL127 \\
\hline 18 & CSIRO Mk3.6.0 & r10i1p1 & $\mathrm{x}$ & $\mathrm{x}$ & $\mathrm{x}$ & $\mathrm{x}$ & $\sim 1.875^{\circ} \times 1.875^{\circ}$ \\
\hline 19 & CSIRO Mk3.6.0 & r1i1p1 & $\mathrm{x}$ & $\mathrm{x}$ & $\mathrm{x}$ & $\mathrm{x}$ & $\sim 1.875^{\circ} \times 1.875^{\circ}$ \\
\hline 20 & CSIRO Mk3.6.0 & r2i1p1 & $\mathrm{x}$ & $\mathrm{x}$ & $\mathrm{x}$ & $\mathrm{x}$ & $\sim 1.875^{\circ} \times 1.875^{\circ}$ \\
\hline 21 & CSIRO Mk3.6.0 & r3i1p1 & $\mathrm{x}$ & $\mathrm{x}$ & $\mathrm{x}$ & $\mathrm{x}$ & $\sim 1.875^{\circ} \times 1.875^{\circ}$ \\
\hline 22 & CSIRO Mk3.6.0 & r4i1p1 & $\mathrm{x}$ & $\mathrm{x}$ & $\mathrm{x}$ & $\mathrm{x}$ & $\sim 1.875^{\circ} \times 1.875^{\circ}$ \\
\hline 23 & CSIRO Mk3.6.0 & r5ilp1 & $\mathrm{x}$ & & $\mathrm{x}$ & $\mathrm{x}$ & $\sim 1.875^{\circ} \times 1.875^{\circ}$ \\
\hline 24 & CSIRO Mk3.6.0 & r6ilp1 & $\mathrm{x}$ & $\mathrm{x}$ & $\mathrm{x}$ & $\mathrm{x}$ & $\sim 1.875^{\circ} \times 1.875^{\circ}$ \\
\hline 25 & CSIRO Mk3.6.0 & r7i1p1 & $\mathrm{x}$ & $\mathrm{x}$ & $\mathrm{x}$ & $\mathrm{x}$ & $\sim 1.875^{\circ} \times 1.875^{\circ}$ \\
\hline 26 & CSIRO Mk3.6.0 & r8i1p1 & $\mathrm{x}$ & $\mathrm{x}$ & $\mathrm{x}$ & $\mathrm{x}$ & $\sim 1.875^{\circ} \times 1.875^{\circ}$ \\
\hline 27 & CSIRO Mk3.6.0 & r9i1p1 & $\mathrm{x}$ & $\mathrm{x}$ & $\mathrm{x}$ & $\mathrm{x}$ & $\sim 1.875^{\circ} \times 1.875^{\circ}$ \\
\hline 28 & FGOALS-g2 & r1i1p1 & $\mathrm{x}$ & $\mathrm{x}$ & & $\mathrm{x}$ & $2.8125^{\circ} \times 2.8125^{\circ}$ \\
\hline 29 & GFDL CM3 & r1i1p1 & $\mathrm{x}$ & $\mathrm{x}$ & $\mathrm{x}$ & $\mathrm{x}$ & $\sim 200 \mathrm{~km} \mathrm{C} 48 \mathrm{~L} 48$ \\
\hline 30 & GFDL-ESM2G & r1i1p1 & $\mathrm{x}$ & $\mathrm{x}$ & $\mathrm{x}$ & $\mathrm{x}$ & $2.5^{\circ}$ longitude, $2^{\circ}$ latitude M45L24 \\
\hline 31 & GFDL-ESM2M & r1i1p1 & $\mathrm{x}$ & $\mathrm{x}$ & $\mathrm{x}$ & $\mathrm{x}$ & $2.5^{\circ}$ longitude, $2^{\circ}$ latitude M45L24 \\
\hline 32 & GISS-E2-R & r1i1p1 & $\mathrm{x}$ & $\mathrm{x}$ & $\mathrm{x}$ & $\mathrm{x}$ & $2^{\circ}$ latitude $\times 2.5^{\circ}$ longitude $\mathrm{F}$ \\
\hline 33 & GISS-E2-R & r2i1p1 & & $\mathrm{x}$ & & & $2^{\circ}$ latitude $\times 2.5^{\circ}$ longitude $\mathrm{F}$ \\
\hline 34 & GISS-E2-R & r3i1p1 & & $\mathrm{x}$ & & & $2^{\circ}$ latitude $\times 2.5^{\circ}$ longitude $\mathrm{F}$ \\
\hline 35 & GISS-E2-R & r4i1p1 & & $\mathrm{x}$ & & & $2^{\circ}$ latitude $\times 2.5^{\circ}$ longitude $\mathrm{F}$ \\
\hline 36 & GISS-E2-R & r5ilp1 & & $\mathrm{x}$ & & & $2^{\circ}$ latitude $\times 2.5^{\circ}$ longitude $\mathrm{F}$ \\
\hline 37 & INM-CM4 & r1i1p1 & & $\mathrm{x}$ & & $\mathrm{x}$ & $2 \times 1.5^{\circ}$ in longitude and latitude latitude-longitude \\
\hline 38 & IPSL-CM5A-LR & r1i1p1 & & $\mathrm{x}$ & $\mathrm{x}$ & $\mathrm{x}$ & $96 \times 95$ equivalent to $1.9^{\circ} \times 3.75^{\circ} \mathrm{LMDZ} 96 \times 95$ \\
\hline 39 & IPSL-CM5A-LR & r2i1p1 & & $\mathrm{x}$ & & $\mathrm{x}$ & $96 \times 95$ equivalent to $1.9^{\circ} \times 3.75^{\circ} \mathrm{LMDZ} 96 \times 95$ \\
\hline 40 & IPSL-CM5A-LR & r3i1p1 & & $\mathrm{x}$ & & $\mathrm{x}$ & $96 \times 95$ equivalent to $1.9^{\circ} \times 3.75^{\circ} \mathrm{LMDZ} 96 \times 95$ \\
\hline 41 & IPSL-CM5A-MR & r1i1p1 & $\mathrm{x}$ & $\mathrm{x}$ & & $\mathrm{x}$ & $144 \times 143$ equivalent to $1.25^{\circ} \times 2.5^{\circ} \mathrm{LMDZ} 144 \times 143$ \\
\hline 42 & MIROC5 & r1i1p1 & $\mathrm{x}$ & $\mathrm{x}$ & $\mathrm{x}$ & $\mathrm{x}$ & $1.40625^{\circ} \times 1.40625^{\circ} \mathrm{T} 85$ \\
\hline 43 & MIROC-ESM & r1i1p1 & $\mathrm{x}$ & $\mathrm{x}$ & $\mathrm{x}$ & $\mathrm{x}$ & $2.8125^{\circ} \times 2.8125^{\circ} \mathrm{T} 42$ \\
\hline 44 & MIROC-ESM-CHEM & r1i1p1 & $\mathrm{x}$ & $\mathrm{x}$ & $\mathrm{x}$ & $\mathrm{x}$ & $2.8125^{\circ} \times 2.8125^{\circ} \mathrm{T} 42$ \\
\hline 45 & MPI-ESM-LR & r1i1p1 & $\mathrm{x}$ & $\mathrm{x}$ & & $\mathrm{x}$ & $\sim 1.8^{\circ} \mathrm{T} 63$ \\
\hline 46 & MPI-ESM-LR & r2i1p1 & $\mathrm{x}$ & $\mathrm{x}$ & & $\mathrm{x}$ & $\sim 1.8^{\circ} \mathrm{T} 63$ \\
\hline 47 & MPI-ESM-LR & r3i1p1 & $\mathrm{x}$ & $\mathrm{x}$ & & $\mathrm{x}$ & $\sim 1.8^{\circ} \mathrm{T} 63$ \\
\hline 48 & MRI-CGCM3 & r1i1p1 & $\mathrm{x}$ & $\mathrm{x}$ & & $\mathrm{x}$ & $320 \times 160$ TL159 \\
\hline 49 & NorESM1-M & r1i1p1 & $\mathrm{x}$ & $\mathrm{x}$ & $\mathrm{x}$ & $\mathrm{x}$ & Finite volume $1.9^{\circ}$ latitude, $2.5^{\circ}$ longitude \\
\hline
\end{tabular}

the proposed methodology could be coupled with a simple hydrologic model to identify the time of emergence of streamflow variables, such as annual flow or low-flow discharges.

Acknowledgments. This research was funded by IDRC Grant 107081-001, Fondecyt Grant 1171133, and
Grants CONICYT/FONDAP/15110017 and 15110020. Scholarships from CONICYT (21160861) and the Sociedad de Canal del Maipo are acknowledged by Cristián Chadwick. We thank the World Climate Research Programme's Working Group on Coupled Modelling and the climate modeling groups for making available their model outputs. We finally thank the referees for their 
constructive suggestions. Data are publicly available from the Dirección General de Aguas, Chile (http:// snia.dga.cl/BNAConsultas/reportes).

\section{APPENDIX}

\section{GCM and RCP Used in the Study}

The GCM and RCP scenarios used in this study are found in Table A1.

\section{REFERENCES}

Akhter, J., L. Das, J. K. Meher, and A. Deb, 2018: Uncertainties and time of emergence of multi-model precipitation projection over homogeneous rainfall zones of India. Climate Dyn., 50, 38133831, https://doi.org/10.1007/s00382-017-3847-y.

Boisier, J. P., and P. Aceituno, 2006: Changes in surface and upperair temperature along the arid coast of northern Chile. Preprints, Eighth Int. Conf. on Southern Hemisphere Meteorology and Oceanography, Foz do Iguaçu, Brazil, Amer. Meteor. Soc., 227-228.

, R. Rondanelli, R. D. Garreaud, and F. Muñoz, 2016: Anthropogenic and natural contributions to the southeast Pacific precipitation decline and recent megadrought in central Chile. Geophys. Res. Lett., 43, 413-421, https://doi.org/10.1002/ 2015 GL067265.

Bown, F., and A. Rivera, 2007: Climate change and recent glacier behaviour in the Chilean Lake District. Global Planet. Change, 59, 79-86, https://doi.org/10.1016/j.gloplacha.2006.11.015.

Brady, R. X., M. A. Alexander, N. S. Lovenduski, and R. R. Rykaczewski, 2017: Emergent anthropogenic trends in California Current upwelling. Geophys. Res. Lett., 44, 5044-5052, https:// doi.org/10.1002/2017GL072945.

Bureau of Reclamation, 2014: Downscaled CMIP3 and CMIP5 climate and hydrology projections: Release of hydrology projections, comparison with preceding information, and summary of user needs. Tech Rep., 110 pp., https://gdo-dcp.ucllnl.org/downscaled_ cmip_projections/techmemo/BCSD5HydrologyMemo.pdf .

Carson, M., A. Köhl, D. Stammer, A. B. A. Slangen, C. A. Katsman, R. S. W. Van de Wal, J. Church, and N. White, 2016: Coastal sea level changes, observed and projected during the 20th and 21st century. Climatic Change, 134, 269-281, https:// doi.org/10.1007/s10584-015-1520-1.

Chadwick, C., J. Gironás, S. Vicuña, F. Meza, and J. McPhee, 2018: Using a statistical pre-analysis approach as an ensemble technique for the unbiased mapping of GCM changes to local stations. J. Hydrometeor., 19, 1447-1465, https://doi.org/10.1175/ JHM-D-17-0198.1.

Diffenbaugh, N. S., and M. Scherer, 2011: Observational and model evidence of global emergence of permanent, unprecedented heat in the 20th and 21st centuries. Climatic Change, 107, 615624, https://doi.org/10.1007/s10584-011-0112-y.

Flato, G. J., and Coauthors, 2013: Evaluation of climate models. Climate Change 2013: The Physical Science Basis, T. F. Stocker et al., Eds., Cambridge University Press, 741-866.

Fowler, H. J., S. Blenkinsop, and C. Tebaldi, 2007: Linking climate change modelling to impacts studies: Recent advances in downscaling techniques for hydrological modelling. Int. J. Climatol., 27, 1547-1578, https://doi.org/10.1002/joc.1556.
Garreaud, R. D., and Coauthors, 2017: The 2010-2015 megadrought in central Chile: Impacts on regional hydroclimate and vegetation. Hydrol. Earth Syst. Sci., 21, 6307-6327, https://doi.org/ 10.5194/hess-21-6307-2017.

Giese, B. S., S. C. Urizar, and N. S. Fučkar, 2002: Southern Hemisphere origins of the 1976 climate shift. Geophys. Res. Lett., 29, 1014, https://doi.org/10.1029/2001GL013268.

Giorgi, F., and X. Bi, 2009: Time of emergence (TOE) of GHGforced precipitation change hot-spots. Geophys. Res. Lett., 36, L06709, https://doi.org/10.1029/2009GL037593.

Harrington, L. J., D. J. Frame, E. M. Fischer, E. Hawkins, M. Joshi, and C. D. Jones, 2016: Poorest countries experience earlier anthropogenic emergence of daily temperature extremes. Environ. Res. Lett., 11, 055007, https://doi.org/10.1088/17489326/11/5/055007.

Hawkins, E., and R. Sutton, 2011: The potential to narrow uncertainty in projections of regional precipitation change. Climate Dyn., 37, 407-418, https://doi.org/10.1007/s00382-010-0810-6.

- and - 2012: Time of emergence of climate signal. Geophys. Res. Lett., 39, L01702, https://doi.org/10.1029/2011GL050087. , and Coauthors, 2014: Uncertainties in the timing of unprecedented climates. Nat., 511, E3-E5, https://doi.org/10.1038/ nature 13523

Henson, S. A., C. Beaulieu, T. Ilyina, J. G. John, M. Long, R. Séférian, J. Tjiputra, and J. L. Sarmiento, 2017: Rapid emergence of climate change in environmental drivers of marine ecosystems. Nat. Commun., 8, 14682, https://doi.org/ 10.1038/ncomms14682.

Keller, K. M., F. Joos, and C. C. Raible, 2014: Time of emergence of trends in ocean biogeochemistry. Biogeosciences, 11, 3647-3659, https://doi.org/10.5194/bg-11-3647-2014.

King, A. D., and Coauthors, 2015: The timing of anthropogenic emergence in simulated climate extremes. Environ. Res. Lett. 10, 094015, https://doi.org/10.1088/1748-9326/10/9/094015.

, M. T. Black, S. K. Min, E. M. Fischer, D. M. Mitchell, L. J. Harrington, and S. E. Perkins-Kirkpatrick, 2016: Emergence of heat extremes attributable to anthropogenic influences. Geophys. Res. Lett., 43, 3438-3443, https://doi.org/10.1002/2015GL067448.

Lee, D., and Coauthors, 2016: Time of emergence of anthropogenic warming signals in the northeast Asia assessed from multiregional climate models. Asia-Pac. J. Atmosp. Sci., 52, 129137, https://doi.org/10.1007/s13143-016-0014-z.

Lehner, F., C. Deser, and L. Terray, 2017: Toward a new estimate of "time of emergence" of anthropogenic warming: Insights from dynamical adjustment and a large initial-condition model ensemble J. Climate, 30, 7739-7756, https://doi.org/10.1175/JCLI-D-16-0792.1.

Leng, G., M. Huang, N. Voisin, X. Zhang, G. R. Asrar, and L. R. Leung, 2016: Emergence of new hydrologic regimes of surface water resources in the conterminous United States under future warming. Environ. Res. Lett., 11, 114003, https://doi.org/ 10.1088/1748-9326/11/11/114003

Liang, X., D. P. Lettenmaier, E. F. Wood, and S. J. Burges, 1994: A simple hydrologically based model of land surface water and energy fluxes for general circulation models. J. Geophys. Res., 99, 14 415-14 428, https://doi.org/10.1029/94JD00483.

— , E. F. Wood, and D. P. Lettenmaier, 1996: Surface soil moisture parameterization of the VIC-2L model: Evaluation and modification. Global Planet. Change, 13, 195-206, https:// doi.org/10.1016/0921-8181(95)00046-1.

Lopez, H., R. West, S. Dong, G. Goni, B. Kirtman, S. K. Lee, and R. Atlas, 2018: Early emergence of anthropogenically forced heat waves in the western United States and Great Lakes. Nat. Climate Change, 8, 414-420, https://doi.org/10.1038/s41558-018-0116-y. 
Lyu, K., X. Zhang, J. A. Church, A. B. Slangen, and J. Hu, 2014: Time of emergence for regional sea-level change. Nat. Climate Change, 4, 1006-1010, https://doi.org/10.1038/nclimate2397.

Mahlstein, I., R. Knutti, S. Solomon, and R. W. Portmann, 2011: Early onset of significant local warming in low latitude countries. Environ. Res. Lett., 6, 034009, https://doi.org/10.1088/ 1748-9326/6/3/034009.

_ , G. Hegerl, and S. Solomon, 2012a: Emerging local warming signals in observational data. Geophys. Res. Lett., 39, L21711, https://doi.org/10.1029/2012GL053952.

_ , R. W. Portmann, J. S. Daniel, S. Solomon, and R. Knutti, 2012b: Perceptible changes in regional precipitation in a future climate. Geophys. Res. Lett., 39, L05701, https://doi.org/ 10.1029/2011GL050738.

Maraun, D., 2013: Bias correction, quantile mapping, and downscaling: Revisiting the inflation issue. J. Climate, 26, 21372143, https://doi.org/10.1175/JCLI-D-12-00821.1.

Massey, F. J., Jr., 1951: The Kolmogorov-Smirnov Test for Goodness of Fit. J. Amer. Stat. Assoc., 46, 68-78, https://doi.org/ 10.1080/01621459.1951.10500769.

Mora, C., and Coauthors, 2013: The projected timing of climate departure from recent variability. Nature, 502, 183-187, https:// doi.org/10.1038/nature12540.

Moss, R. H., and Coauthors, 2010: The next generation of scenarios for climate change research and assessment. Nature, 463, 747756, https://doi.org/10.1038/nature08823.

Muir, L. C., J. N. Brown, J. S. Risbey, S. E. Wijffels, and A. S. Gupta, 2013: Determining the time of emergence of the climate change signal at regional scales. CAWCR Research Letters, No. 10, CAWCR, Aspendale, Australia, 8-19, https://www.cawcr.gov.au/ researchletters/CAWCR_Research_Letters_10.pdf.

Myers, D., 1994: Spatial interpolation: An overview. Geoderma, 62, 17-28, https://doi.org/10.1016/0016-7061(94)90025-6.

Nguyen, T. H., S. K. Min, S. Paik, and D. Lee, 2018: Time of emergence in regional precipitation changes: An updated assessment using the CMIP5 multi-model ensemble. Climate Dyn., 51, 3179-3193, https://doi.org/10.1007/s00382-018-4073-y.

Pierce, D. W., and Coauthors, 2013: The key role of heavy precipitation events in climate model disagreements of future annual precipitation changes in California. J. Climate, 26, 5879-5896, https://doi.org/10.1175/jcli-d-12-00766.1.

Rosenblüth, B., H. A. Fuenzalida, and P. Aceituno, 1997: Recent Temperature Variations Southern South America. Int. J. Climatol., 17, 67-85, https://doi.org/10.1002/(SICI)1097-0088(199701) 17:1<67::AID-JOC120>3.0.CO;2-G.

Sokol Jurković, R., and Z. Pasarić, 2013: Spatial variability of annual precipitation using globally gridded data sets from 1951 to 2000. Int. J. Climatol., 33, 690-698, https://doi.org/10.1002/joc.3462.

Sui, Y., X. Lang, and D. Jiang, 2014: Time of emergence of climate signals over China under RCP4.5 scenario. Climatic Change, 125, 265-276, https://doi.org/10.1007/s10584-014-1151-y.

Taylor, K. E., R. J. Stouffer, and G. A. Meehl, 2012: An overview of CMIP5 and the experiment design. Bull. Amer. Meteor. Soc., 93, 485-498, https://doi.org/10.1175/BAMS-D-11-00094.1.

Trenberth, K. E., 1990: Recent observed interdecadal climate change in the Northern Hemisphere. Bull. Amer. Meteor. Soc., 71, 988-993, https://doi.org/10.1175/1520-0477(1990) $071<0988$ :ROICCI $>2.0 . \mathrm{CO} ; 2$.

, and D. P. Stepaniak, 2001: Indices of El Niño evolution. J. Climate, 14, 1697-1701, https://doi.org/10.1175/1520-0442(2001) 014<1697:LIOENO>2.0.CO;2.

University of Washington, 2014: Time of emergence of climate change signals in the Puget Sound Basin Project. University of Washington Project Rep., 74 pp., https:/www.eopugetsound.org/sites/default/ files/ToE_Project_Report.pdf.

Wilby, R. L., and T. M. L. Wigley, 1997: Downscaling general circulation model output: A review of methods and limitations. Prog. Phys. Geogr., 21, 530-548, https://doi.org/10.1177/ 030913339702100403

Zhou, T., N. Voisin, G. Leng, M. Huang, and I. Kraucunas, 2018: Sensitivity of regulated flow regimes to climate change in the western United States. J. Hydrometeor., 19, 499-515, https:// doi.org/10.1175/JHM-D-17-0095.1.

Zhuan, M. J., J. Chen, M. X. Shen, C. Y. Xu, H. Chen, and L. H. Xiong, 2018: Timing of human-induced climate change emergence from internal climate variability for hydrological impact studies. Hydrol. Res., 49, 421-437, https://doi.org/ 10.2166/nh.2018.059 